\title{
Meningkatkan motivasi dan efikasi diri penderita diabetes tipe 2 dalam pencegahan kaki diabetik menggunakan dukungan kelompok
}

\author{
Suyanto ${ }^{1 *}$, Dwi Sulistyowati ${ }^{2}$ \\ 1,2 Politeknik Kesehatan Surakarta Jurusan Keperawatan. *Email: suyanto.mkes@gmail.com
}

\begin{abstract}
Improving motivation and self-efication of type 2 diabetics in prevention of diabetic foot ulcers and infections using group support
\end{abstract}

Background: Management of DM (Diabetics) patients according to expectations requires a variety of support, one of them is group support such as the Persadia Club as an organization that helps people with diabetes to manage disease conditions become more controlled. Through group support, motivation and self-efficacy which are important factors in diabetes care behavior will increase. Thus the main action in the prevention of diabetic foot in the form of routine foot care will be carried out by the person with diabetes optimally.

Purpose: To determine the effect of group support on motivation and self-efficacy of type 2 diabetics in prevention of diabetic foot ulcers and infections

Methods: The study design was a quasi-experimental one pre group test one group method to see if there were differences in motivation and self-efficacy in diabetic foot care before and after group support. The study was conducted in May to August 2019 at the Surakarta City Persada Club as a population and a sample of 135 respondent

Results: Research shows that there are differences in the self-efficacy of people with diabetes before and after getting group support with $p$ value $=0,000$. Thus the hypothesis that the influence of group support on selfefficacy is accepted. Furthermore, the results obtained that there are differences in motivation to take preventive measures for diabetes feet between before and after group support is given with a $p$ value $=0,000$. This means that the hypothesis that there is an influence of group support on motivation for diabetic foot prevention.

Conclusion: As a suggestion, it is expected that people with diabetes through the Persadia club will always be supported so that their motivation and efficacy is high so that the diabetic foot care measures will be optimally carried out.

Keywords: Motivation; Self-Efication; Type 2 Diabetics; Prevention; Diabetic Foot Ulcers and Infections; Group Support

Pendahuluan: Pengelolaan pasien DM (Diabetisi) yang sesuai harapan memerlukan berbagai dukungan salah satu diantaranya yaitu dukungan kelompok seperti Club persadia sebagai organisasi yang membantu para diabetisi untuk mengelola kondisi penyakit menjadi lebih terkontrol. Melalui dukungan kelompok maka motivasi dan efikasi diri yang merupakan faktor penting dalam perilaku perawatan diabetes akan meningkat. Dengan demikian tindakan utama dalam pencegahan kaki diabetik berupa tindakan perawatan kaki secara rutin akan dilakukan para diabetisi dengan optimal.

Tujuan: Untuk mengetahui pengaruh dukungan kelompok terhadap motivasi dan efikasi diri penderita diabetes tipe 2 dalam pencegahan kaki diabetik

Metode : Rancangan penelitian berupa kuasi eksperimen dengan metode pre post test one group untuk melihat apakah terdapat perbedaan motivasi dan efikasi diri dalam tindakan perawatan kaki diabetik sebelum dan sesudah mendapat dukungan kelompok. Penelitian dilakukan pada bulan Mei hingga Agustus 2019 pada Club Persadia Kota Surakarta sebagai populasi dan diambil sampel sebanyak 135 responden

Hasil: Penelitian menunjukkan bahwa terdapat perbedaan efikasi diri para diabetisi sebelum dan sesudah mendapt dukungan kelompok dengan $p$ value $=0,000$, Dengan demikian hipotesis terdapat pengaruh dukungan kelompok terhadap efikasi diri diterima. Selanjutnya diperoleh hasil bahwa terdapat perbedaan motivasi melakukan 
tindakan perawatan pencegahan kaki diabetes antara sebelum dan sesudah diberikan dukungan kelompok dengan nilai $p$ value $=0,000$. Hal ini berarti hipotesis terdapat pengaruh dukungan kelompok terhadap motivasi tindakan perawatan pencegahan kaki diabetis.

Simpulan: Sebagai saran diharapkan para diabetisi melalui club Persadia selalu diberi dukungan agar motivasi dan efikasi dirinya tinggi sehingga tindakan perawatan kaki diabetik akan optimal dilakukan.

\section{Kata Kunci : Motivasi; Efikasi Diri; Penderita Diabetes Tipe 2; Pencegahan Kaki Diabetik; Dukungan Kelompok}

\section{PENDAHULUAN}

Diabetes Mellitus (DM) adalah penyakit yang tidak menular yang meningkat jumlahnya dan menjadi penyebab angka kesakitan dan kematian. Kesembuhan Diabetes Mellitus tergantung pada pasien itu sendiri, yaitu dengan mengenali gejala dan memahami atau mengelola penyakit DM. Pasien yang memiliki pengetahuan tentang Diabetes Mellitus dan komplikasinya akan berhasil melawan penyakit DM.

Pengelolaan penyakit DM dapat dilakukan dengan pengendalian kadar glukosa darah sampai mendekati normal akan mencegah terjadinya komplikasi Diabetes Mellitus (Soegondo, 2015). Kemampuan penderita mendeteksi dini kadar gula darah merupakan kadar indikator penting dalam pengendalian Diabetes Mellitus untuk dapat mempertahankan kualitas hidupnya.

Pada tahun 2015 angka kejadian diabetes di seluruh dunia mencapai 415 juta jiwa, dan pada tahun 2040 di perkirakan pada tahun 2040 menjadi 642 juta jiwa (World Health Organization, 2016). Sedangkan diabetisi di Indonesia menempati urutan ke-7 di seluruh dunia dengan 8,5 juta jiwa dan urutan ke-6 untuk kasus kematian sebelum berusia 70 tahun akibat DM (International Diabetes Federation, 2015).

Di kota Surakarta berdasarkan laporan Dinas Kesehatan Kota Surakarta tahun 2017 terjadi perubahan prevalensi DM khususnya tipe 2 mencapai 6.579 kasus pada tahun 2017. Peningkatan prevalensi tersebut disebabkan beberapa faktor risiko antara lain riwayat DM keluarga, usia > 45 tahun, pola makan yang buruk, aktivitas fisik yang kurang, dan merokok, hipertensi dan kelebihan kadar kolesterol (obesitas) (Sukmaningsih, 2016).

Komplikasi diabetes dapat berupa komplikasi kronik, seperti ulkus diabetik. Tetapi dengan pendidikan manajemen diri diabetes penderita memiliki kemampuan dalam melakukan perawatan diri seperti mencegah mencegah ulkus diabetik (Yuanita, Wantiyah, \& Susanto, 2014). Komplikasi tersebut tidak akan muncul apabila perawatan diabetes dilaksanakan dengan baik, tertib, dan teratur. Oleh karena itu, pengelolaan atau manajemen diri diabetes merupakan hal yang sangat penting. Secara umum manajemen diri pada pasien diabetes adalah adanya keterlibatan pasien terhadap seluruh aspek pada penyakit diabetes dan implikasinya, termasuk manajemen medis, perubahan dalam peran sosial dan pekerjaan, serta coping. Manajemen diri adalah istilah yang merupakan hasil dari hubungan kolaboratif antara pasien, dokter, dan tenaga kesehatan lain. Agar mendapatkan hasil yang sebaik baiknya maka manajemen diri dipadukan dengan perawatan diri yaitu hal yang dikerjakan pasien dengan caranya sendiri dalam pengelolaan penyakitnya. Sebagai penyakit kronis, satusatunya cara yang dapat dilakukan pasien adalah melakukan manajemen diri, agar terhindar atau memperlambat munculnya komplikasi. Banyak faktor psikososial yang berpengaruh dalam manajemen diri seperti motivasi dan efikasi diri, dukungan keluarga dan dukungan kelompok. Salah satu komplikasi yang sangat ditakuti oleh penderita diabetes adalah Diabetic Foot/ kaki diabetik. Komplikasi ini terjadi karena terjadinya kerusakan saraf, pasien tidak dapat membedakan suhu panas dan dingin, dimana sensifitas rasa sakit pun berkurang. Hal tersebut disebabkan oleh kerusakan pada saraf sehingga terjadi penurunan kemampuan merasakan nyeri atau menjadi baal akibatnya sering kali pengidap diabetes tidak menyadari adanya luka. Selain itu, kulit pada kaki menjadi kering dan mudah pecah sehingga mudah terjadi borok dan infeksi.

Beberapa hal yang dapat diupayakan agar manajemen diri pasien DM dapat menghasilkan kondisi yang dapat diharapkan adalah adanya dukungan sosial yang dapat berupa dukungan keluarga dan dukungan kelompok. Kemudian kondisi efikasi diri pasien dan motivasi untuk melakukan perawatan kaki harus tinggi. Selfefficacy merupakan faktor penting dalam perilaku 
Meningkatkan motivasi dan efikasi diri penderita diabetes tipe 2 dalam pencegahan kaki diabetik menggunakan dukungan kelompok

perawatan diabetes bahkan Self-efficacy merupakan salah satu faktor yang terlibat dalam keberhasilan manajemen perawatan diri penderita diabetes melitus tipe 2 (Silolonga, 2018). Untuk itu sangat perlu dilakukan pengukuran untuk mengetahui level self-efficacy yang dimiliki pasien. Level self-efficacy yang rendah menjadi ukuran bagi petugas kesehatan untuk membuat perencanaan meningkatkan self-efficacy pasien (Gao, Wang, Zheng, Haardörfer, Kegler, Zhu, \& $\mathrm{Fu}, 2013)$.

Perawatan kaki secara teratur dapat mengurangi resiko kejadian kaki diabetik sebesar $50-60 \%$. Tetapi untuk melakukannya harus memiliki kemauan dan niat yaitu motivasi dan efikasi diri yang tinggi karena perawatan kaki diabetik ini harus dilakukan secara teratur. Adapun perawatan kaki diabetes yang merupakan aktivitas khusus terdiri dari senam kaki, memeriksa dan merawat kaki yang dilakukan individu yang beresiko sebagai upaya dalam mencegah timbulnya ulkus diabetikum.

Berdasarkan teori kognitif sosial, dukungan kelompok dan efikasi diri serta perilaku pencegahan kaki diabetik harus menjadi perhatian agar tidak terjadi komplikasi lebih lanjut. Hal tersebut merupakan aspek aspek dalam pengelolaan penyakit DM sehingga diperlukan kajianya dalam sebuah penelitian.

Dukungan kelompok seperti club persadia sebagai organisasi yang membantu para diabetisi untuk mengelola kondisi penyakit menjadi lebih terkontrol sangat diperlukan. Bentuk dukungan yang diperoleh dari Persadia berupa dukungan emosional, dukungan penghargaan atau harga diri, dukungan instrumental dan dukungan informasi dari kelompok.

Pemilihan motivasi dan efikasi diri sebagai variabel yang dikaji berdasarkan pada penelitian lalu yang menyebutkan bahwa terdapat hubungan diantara keduanya (Ariani, Sitorus, \& Gayatri, 2012). Namun belum diketahui motivasi perawatan kaki dan efikasi diri apakah dapat dipengaruhi oleh dukungan kelompok. Harapannya bila telah diketahui maka perawat dapat meningkatkan motivasi dan efikasi diri dengan menggunakan dukungan kelompok dalam rangka mencegah terjadinya kaki diabetik.

\section{METODE PENELITIAN}

Quasi eksperiment dipilih dengan metode pre test - post test karena ingin melihat apakah terdapat pengaruh dukungan kelompok terhadap efikasi diri dan motivasi perawatan pencegahan kaki diabetik. Club Persadia kota Surakarta menjadi tempat pengumpulan dan yang dilakukan mulai bulan Mei sampai September tahun 2019. Adapun yang menjadi populasi adalah penderita Diabetes Melitus tipe II yang belum menderita ulkus diabetikum serta menjadi anggota Club Persadia kota Surakarta sebanyak 200 orang. Selanjutnya ditetapkan sampel yang diambil sebagai responden menggunakan tabel Krecjie sebanyak 135 orang.

Data dikumpulkan menggunakan kuesioner efikasi yang diadopsi dari DSES (Silolonga, 2018) yang telah diuji coba memiliki Nilai Content Validity Index $(\mathrm{CVI}) \geq 0.80$ dan cronbach"s alpha 0.828 serta nilai korelasi test-retest $r=0.721$ $(p, 0.000)$. Sedangkan data motivasi perawatan kaki diabetik menggunjakan cek list yang diadopsi dan telah diuji validitas dan reliabilitasnya dengan hasil nilai alpha Cronbach 0,930 (Arianti, 2015).

Kegiatan pengumpulan data dilakukan dengan membagikan kuesioner pre test efikasi diri dan perawatan kaki. Kemudian mengobservasi kehadiran dan aktifitas responden dalam kegiatan Club Persadia. Selanjutnya membagikan buku panduan dan perlengkapan perawatan pencegahan kaki diabetikum. 4 minggu kemudian sebagai tahap akhir dibagikan kuesioner post test. 
Meningkatkan motivasi dan efikasi diri penderita diabetes tipe 2 dalam pencegahan kaki diabetik menggunakan dukungan kelompok

HASIL

Tabel 1. Karakteristik Responden ( $\mathrm{N}=135$ )

\begin{tabular}{|c|c|c|c|c|c|c|}
\hline \multirow{3}{*}{ Variabel } & \multicolumn{4}{|c|}{ Usia } & \multirow{2}{*}{\multicolumn{2}{|c|}{ Total }} \\
\hline & \multicolumn{2}{|c|}{$<60$ th } & \multicolumn{2}{|c|}{$\geq 60$ th } & & \\
\hline & $\mathrm{n}$ & $\%$ & $\mathrm{n}$ & $\%$ & $\mathbf{N}$ & $\%$ \\
\hline \multicolumn{7}{|l|}{ Jenis Kelamin } \\
\hline Pria & 6 & 11 & 30 & 37,5 & 36 & 27 \\
\hline Wanita & 49 & 89 & 50 & 62,5 & 99 & 73 \\
\hline \multicolumn{7}{|l|}{ Pendidikan } \\
\hline Tidak sekolah & 4 & 7 & 15 & 19 & 19 & 14 \\
\hline SD & 10 & 18 & 30 & 38 & 40 & 30 \\
\hline SMP & 25 & 46 & 10 & 12 & 35 & 26 \\
\hline SMA & 11 & 20 & 20 & 25 & 31 & 23 \\
\hline PT & 5 & 9 & 5 & 6 & 10 & 7 \\
\hline Jumlah & 55 & 41 & 80 & 59 & 135 & 100 \\
\hline
\end{tabular}

Kebanyakan responden memiliki karakteristik yang hampir sama yaitu banyak berjenis kelamin wanita dan berusia lebih dari 60 tahun serta berpendidikan menengah sebagai mana dapat dilihat pada tabel 1. Sebagaimana telah diketahui bahwa efikasi diri adalah gagasan kunci dari teori sosial kognitif, dan efikasi diri mempengaruhi bagaimana seseorang berpikir, merasa, memotivasi diri sendiri dan bertindak. Efikasi diri mendorong proses kontrol diri untuk mempertahankan perilaku yang dibutuhkan (Bandura, Evans, \& Huberman, 1988; Zimmerman, 2000; Katuuk, \& Kallo, 2019). Efikasi diri responden nampak tinggi, hal tersebut terlihat pada tabel 2 terlihat bahwa efikasi diri responden yang tinggi $(60,7 \%)$ meskipun belum mendapatkan perlakuan dukungan kelompok.

Tabel 2. Distribusi Frekuensi Efikasi Diri Responden $(\mathrm{N}=135)$

\begin{tabular}{lcccc}
\hline Efikasi Diri & \multicolumn{2}{c}{$\begin{array}{c}\text { Sebelum Mendapat } \\
\text { Dukungan Kelompok }\end{array}$} & \multicolumn{2}{c}{$\begin{array}{c}\text { Sesudah Mendapat } \\
\text { Dukungan Kelompok }\end{array}$} \\
\cline { 2 - 5 } & $\begin{array}{c}\text { Frekuensi } \\
\text { (f) }\end{array}$ & $\begin{array}{c}\text { Persentase } \\
(\%)\end{array}$ & $\begin{array}{c}\text { Frekuensi } \\
(\mathbf{f})\end{array}$ & $\begin{array}{c}\text { Persentase } \\
(\%)\end{array}$ \\
\hline Tinggi & 82 & 60,7 & 118 & 87,4 \\
Rendah & 53 & 39,3 & 17 & 12,6 \\
Jumlah & 135 & 100 & 135 & 100 \\
\hline
\end{tabular}

Efikasi diri mereka sebagian besar menjadi lebih tinggi lagi setelah mendapatkan perlakuan berupa dukungan kelompok seperti senam bersama, penyuluhan, pembagian buku panduan perawatan kaki dan pemeriksaan gula darah sewaktu yang diberikan secara gratis sebagaimana dapat dilihat pada tabel 2. Efikasi diri atau Self-efficacy responden telah diketahui menjadi tinggi yang mana efikasi diri merupakan faktor penting dalam perilaku perawatan diabetes sehingga perlu dilakukan pengukuran untuk mengetahui level self-efficacy yang dimiliki pasien. Level self-efficacy yang rendah menjadi ukuran bagi petugas kesehatan untuk membuat perencanaan untuk meningkatkan self-efficacy pasien (Gao et al., 2013).

Perawatan kaki merupakan tindakan yang bersifat preventif memerlukan motivasi untuk menjalankannya dan responden sebelum mendapatkan perlakuan berupa dukungan kelompok sebagian besar memiliki motivasi melakukan perawatan pencegahan kaki diabetik yang rendah sebagaimana dapat dilihat pada tabel 3 . 
Meningkatkan motivasi dan efikasi diri penderita diabetes tipe 2 dalam pencegahan kaki diabetik menggunakan dukungan kelompok

Tabel 3 Distribusi Frekuensi Motivasi Perawatan Pencegahan Kaki Diabetik Responden ( $N=135)$

\begin{tabular}{|c|c|c|c|c|}
\hline \multirow{2}{*}{$\begin{array}{l}\text { Motivasi } \\
\text { Perawatan } \\
\text { Pencegahan kaki } \\
\text { diabetik }\end{array}$} & \multicolumn{2}{|c|}{$\begin{array}{c}\text { Sebelum Mendapat } \\
\text { Dukungan Kelompok }\end{array}$} & \multicolumn{2}{|c|}{$\begin{array}{l}\text { Sesudah Mendapat } \\
\text { Dukungan Kelompok }\end{array}$} \\
\hline & $\begin{array}{l}\text { Frekuensi } \\
\text { (f) }\end{array}$ & $\begin{array}{l}\text { Persentase } \\
(\%)\end{array}$ & $\begin{array}{l}\text { Frekuensi } \\
\text { (f) }\end{array}$ & $\begin{array}{c}\text { Persentase } \\
(\%)\end{array}$ \\
\hline Tinggi & 61 & 45,2 & 124 & 91,9 \\
\hline Rendah & 74 & 54,8 & 11 & 8,1 \\
\hline Jumlah & 135 & 100 & 135 & 100 \\
\hline
\end{tabular}

Motivasi responden melakukan perawatan pencegahan kaki diabetik menjadi tinggi sesudah mendapat perlakuan berupa dukungan kelompok seperti senam kaki, penyuluhan perawatan kaki, pemberian buku panduan perawatan kaki. Hal tersebut sebagaimana dapat dilihat pada tabel 3.

Pembuktian adanya pengaruh dukungan kelompok terhadap efikasi diri penderita Diabetes tipe 2 dilakukan dengan analisa menggunakan uji Wilcoxon. Hasil analisa dapat dilihat pada tabel 4 yang menunjukkan $p$ value sebesar $0,000<0,05$. Dengan demikian hipotesis penelitian ini yaitu: Terdapat pengaruh (diterima) dukungan kelompok terhadap efikasi diri penderita diabetis tipe 2.

Tabel 4. Efikasi Diri Dan Motivasi Responden Dengan Dukungan Kelompok.

\begin{tabular}{lcccc}
\hline Variabel & Mean & Median & Nilai Z & $p$-value \\
& & & & \\
\hline Efikasi diri & & & & \\
$\begin{array}{l}\text { Responden } \\
\text { Sebelum }\end{array}$ & 63,1 & 56 & $-4,762$ & 0,000 \\
$\begin{array}{l}\text { Sesudah } \\
\text { Motivasi }\end{array}$ & 74,5 & 67 & & \\
Responden & & & & \\
Sebelum & 59,4 & 60 & $-6,196$ & 0,000 \\
Sesudah & 75,8 & 79 & & \\
\hline
\end{tabular}

Selanjutnya pembuktian adanya pengaruh dukungan kelompok terhadap motivasi perawatan pencegahan kaki diabetik penderita Diabetes tipe 2 dilakukan juga dengan menggunakan uji Wilcoxon. Hasil analisa dapat dilihat pada tabel 4 yang menunjukan $p$ value sebesar $0,000<0,05$. Dengan demikian hipotesis:Terdapat pengaruh (diterima) dukungan kelompok terhadap motivasi perawatan pencegahan kaki diabetik pada diabetisi tipe 2.

\section{PEMBAHASAN}

\section{Dukungan Kelompok dan Efikasi Diri}

Berdasarkan analisa data penelitian yang telah dilakukan menunjukan hasil bahwa ada pengaruh dukungan kelompok terhadap efikasi diri para diabetisi. Hal tersebut dapat dijelaskan bahwa dukungan kelompok seperti club persadia sebagai organisasi sangat membantu para diabetisi untuk mengelola kondisi penyakit menjadi lebih terkontrol. Dukungan yang akan didapat antara lain dukungan emosional, dukungan penghargaan atau harga diri, dukungan instrumental, dan dukungan informasi dari kelompok.

Dengan demikian efikasi diri sangat diperlukan bagi pasien Diabetes Mellitus (DM) tipe 2 untuk meningkatkan kemandirian pasien dalam mengelola penyakitnya. Hal ini didukung oleh hasil penelitian yang pernah dilakukan bahwa terdapat hubungan antara motivasi dan efikasi diri pasien DM tipe 2. (Ariani et al., 2012).

Penelitian senada pernah juga dilakukan untuk melihat motivasi pasien DM tipe 2 yang sering berfluktuasi disebabkan oleh perawatan yang lama dan biaya yang besar sehingga menimbulkan masalah psikologis seperti frustasi, cemas, dan depresi. Masalah psikologis ini dapat mempengaruhi motivasi pasien untuk melakukan perawatan diri. Tingkat motivasi pasien yang rendah dapat mempengaruhi efikasi diri klien, 
Meningkatkan motivasi dan efikasi diri penderita diabetes tipe 2 dalam pencegahan kaki diabetik menggunakan dukungan kelompok

sehingga manajemen perawatan diri pasien DM tersebut tidak dapat berjalan dengan baik. Manajemen diri yang berjalan kurang baik akan berdampak pada keberhasilan penatalaksanaan pasien DM (Winahyu, Badawi, \& Setyoningrum, 2016).

Agar efikasi diri pasien yang menderita diabetes tinggi diperlukan dukungan baik dukungan kelompok ataupun dukungan keluarga dan dukungan sosial sebagai support system pada pasien. Hal tersebut pernah diteliti dengan hasil bahwa dukungan keluarga pada lansia DM tipe 2 sangat penting dalam manajemen diabetes, dimana anggota keluarga sangat terlibat dalam banyak aspek kegiatan perawatan kesehatan yang diperlukan pasien diabetes. Kesimpulan penelitian tersebut yaitu bahwa adanya dukungan keluarga yang besar dapat meningkatkan efikasi diri penderita (Ramadhani, Agusman, \& Hadi, 2016).

Memperkuat hasil penelitian yang menyatakan bahwa pentingnya dukungan kelompok pada penderita diabetes adalah penelitian mengenai diabetisi di puskesmas Pakis Surabaya. Para penderita mendapat dukungan melalui keterlibatan aktif dalam kelompok seperti pertukaran informasi dan pembuatan keputusan mengenai kesehatannya. Dukungan kelompok yang baik berfungsi sebagai sistem pendukung bagi anggotanya dengan cara meningkatkan dukungan emosional, penghargaan, instrumental, dan informatif yang diberikan oleh anggotanya (Syailendrawati \& Endang, 2012; Dewi, \& Hamid, 2011).

Pelaksanaan penelitian ini dilakukan menggunakan kegiatan dukungan kelompok yang diberikan pada responden meliputi : Senam setiap hari minggu, pendidikan kesehatan khususnya perawatan pencegahan kaki diabetik, pemberian buku panduan perawatan kaki diabetik, pemberian peralatan perawatan kaki, dan pemeriksaan gula darah sewaktu. Metode pemberian dukungan kelompok yang dilakukan tersebut sejalan dengan hasil penelitian yang menyatakan bahwa dukungan kelompok yang merupakan faktor dukungan sosial dapat meningkatkan upaya penyembuhan dan pengobatan (Syailendrawati \& Endang, 2012).

Keterlibatan dalam kelompok merupakan keterlibatan individu dalam proses yang terkait dengan tugas kelompok seperti pertukaran informasi dan pembuatan keputusan kolaboratif dan seberapa banyak individu merasa dihormati dan didengarkan dalam kelompok. Penelitian sebelumnya di pada club ini juga didapatkan bahwa dukungan kelompok diperlukan agar kualitas hidup diabetisi meningkat dengan adanya peningkatan upaya penyembuhan dan pengobatan (Ismail, 2016). Dengan demikian berdasarkan beberapa penelitian terdahulu yang sejalan dan mendukung serta memperkuat hasil penelitian ini dapat disimpulkan bahwa pada dasarnya dukungan kelompok sangat diperlukan oleh penderita diabetes agar masalah pengelolaan perawatan diri yang diupayakan menjadi lebih baik karena adanya efikasi diri yang tinggi.

\section{Dukungan Kelompok dan Motivasi Perawatan Pencegahan kaki diabetik}

Tindakan perawatan kaki bagi penderita diabetes yang bersifat preventif mencakup tindakan mencuci kaki dengan benar, mengeringkan dan meminyakinya; harus dilakukan hati-hati agar jangan sampai celah di antara jari-jari kaki tidak menjadi luka dan basah membutuhkan motivasi yang tinggi untuk melakukannya. Terlebih lagi bila mengingat bahwa tindakan perawatan kaki ini harus dilakukan dengan cara memeriksa kaki setiap hari untuk melihat apakah terdapat gejala kemerahan, lepuh, fisura, kalus, atau ulserasi (Sihombing, Nursiswati, \& Prawesti, 2012; Katu, 2016).

Berdasarkan analisa data penelitian ini diperoleh hasil bahwa terdapat pengaruh dukungan kelompok terhadap motivasi perawatan pencegahan kaki diabetik para penderita diabetes, hasil penelitian ini didukung oleh penelitian tentang pengaruh program edukasi perawatan kaki berbasis keluarga terhadap perilaku perawatan kaki pada pasien diabetes melitus tipe 2 . Menurut penelitian tersebut, perilaku perawatan kaki merupakan komponen yang penting dalam pencegahan kaki diabetik. Namun banyak pasien Diabetes Melitus (DM) yang tidak menjalankannya akibat rendahnya pengetahuan dan self-efficacy pasien maupun keluarga (Sari, Haroen, \& Nursiswati, 2016; Muharram, \& Maliya, 2018).

Permasalahan perawatan pencegahan kaki diabetik kiranya harus menjadi perhatian serius karena menurut penelitian yang pernah dilakukan menunjukkan bahwa salah satu komplikasi penyakit diabetes melitus yang sering dijumpai adalah kaki diabetik (diabetic foot) (Hidayat \& Nurhayati, 2014). Komplikasi tersebut dapat bermanifestasikan sebagai ulkus, infeksi dan 
Meningkatkan motivasi dan efikasi diri penderita diabetes tipe 2 dalam pencegahan kaki diabetik menggunakan dukungan kelompok

gangren serta artropati Charcot. Penderita diabetes mempunyai resiko $15 \%$ mengalami ulkus kaki diabetik pada masa hidupnya dan mempunyai resiko terjadi kekambuhan dalam 5 tahun sebesar $70 \%$. Selain itu neuropati perifer, penyakit vaskuler perifer, beban tekanan abnormal pada plantar dan infeksi menjadi resiko penting untuk terjadinya ulkus kaki diabetik dan amputasi, oleh karena itu perawatan kaki penderita Diabetes harus menjadi tindakan utama dan rutin dilakukan mengingat bahwa ulkus kaki diabetes merupakan komplikasi yang berkaitan dengan morbiditas akibat dari komplikasi mikro dan makrovaskuler. Sebagaimana diketahui bahwa ulkus kaki diabetes sering diawali dengan cedera pada jaringan lunak kaki, pembentukan fisura antara jari-jari kaki atau di daerah kulit yang kering, atau pembentukan sebuah kalus yang dapat dideteksi saat melakukan tindakan perawatan kaki (Hidayat, \& Nurhayati, 2014; Rosikhoh, 2016)

Kondisi diabetic foot sering diawali oleh cidera yang tidak dirasakan oleh pasien yang kepekaan kakinya sudah menghilang dan bisa berupa cedera termal (misalnya, berjalan dengan kaki telanjang di jalan yang panas, atau memeriksa air panas untuk mandi dengan menggunakan kaki), cidera kimia (misalnya, membuat kaki terbakar pada saat menggunakan preparat kaustik untuk menghilangkan kalus, veruka atau bunion), atau cidera traumatik (misalnya, melukai kulit ketika menggunting kuku kaki, menginjak benda asing dalam sepatu, atau mengenakan kaus kaki yang tidak pas). Hal di atas dapat dicegah dengan melakukan tindakan perawatan kaki. Oleh karena pentingnya tindakan perawatan kaki maka perawat harus meningkatkan motivasi para penderita diabetes untuk melakukan tindakan perawatan pencegahan kaki diabetik. Hal ini didukung oleh penelitian yang pernah dilakukan bahwa perawat dapat meningkatkan motivasi dan efikasi diri pasien melalui klub diabetes mengguinakan dukungan sosial (Ariani et al., 2012).

Selain itu juga pernah dilakukan penelitian yang mendukung hasil penelitian ini yang menyebutkan bahwa terdapat pengaruh dukungan kelompok terhadap motivasi penderita diabetes untuk melakukan tindakan perawatan kaki yaitu penelitian tentang program edukasi perawatan kaki berbasis dukungan keluarga yang terbukti efektif meningkatkan perilaku perawatan kaki pasien (Sari et al., 2016)

\section{SIMPULAN}

Penderita diabetis tipe 2 memerlukan dukungan kelompok seperti melalui Club Persadia agar efikasi dirinya meningkat. Selain itu dukungan kelompok juga diperlukan untuk mempengaruhi motivasi penderita melakukan tindakan perawatan kaki dan pencegahan komplikasi penyakit Diabetes Melitus dapat dilakukan dengan sebaik baiknya.

\section{DAFTAR PUSTAKA}

Ariani, Y., Sitorus, R., \& Gayatri, D. (2012). Motivasi dan Efikasi Diri Pasien Diabetes Melitus Tipe 2 dalam Asuhan Keperawatan. Jurnal Keperawatan Indonesia. https://doi.org/10.7454/jki.v15i1.44 29-38

Arianti, A. (2015). Hubungan Antara Perawatan Kaki dengan Risiko Ulkus Kaki Diabetes di Rumah Sakit PKU Muhammadiyah Yogyakarta. IJNP (Indonesian Journal of Nursing Practices), vol 2, No. Retrieved from http:/journal.umy.ac.id/index.php/ijnp/article/vie w/665/817

Bandura, A., Evans, R. I., \& Huberman, B. (1988). Albert Bandura. na.

Dewi, E. I., \& Hamid, A. Y. S. (2011). Pengaruh Terapi Kelompok Suportif terhadap Tingkat Ansietas Keluarga dalam Merawat Anak Tunagrahita. Jurnal Keperawatan Soedirman, 7(1), 17-24.

Gao, J., Wang, J., Zheng, P., Haardörfer, R., Kegler, M. C., Zhu, Y., \& Fu, H. (2013). Effects of self-care, self-efficacy, social support on glycemic control in adults with type 2 diabetes. BMC Family Practice. https://doi.org/10.1186/1471-2296-14-66

Hidayat, A. R., \& Nurhayati, I. (2014). Perawatan Kaki Pada Penderita Diabetes Militus di Rumah. Jurnal Permata Indonesia. Retrieved from http://www.permataindonesia.ac.id/wpcontent/uploads/2015/07/201406.pdf 
International Diabetes Federation. (2015). Persatuan Diabetes Indonesia. Retrieved from https://www.idf.org/our-network/regionsmembers/western-pacific/members/104indonesia.html?layout=details\&mid=153

Ismail, M. H. (2016). Pengaruh Dukungan Kelompok Terhadap Kulaitas Hidup Penderita Diabetes Melitus Di Persadia Cabang Surakarta. Retrieved from http://eprints.ums.ac.id/47914/23/Naskah Publikasi.pdf

Katu, A. N. D. (2016). Studi Kualitatif: Persepsi Pasien Diabetes Mellitus Tipe li Tentang Perawatan Kaki Di Puskesmas Kotagede 1 Yogyakarta (Doctoral dissertation, STIKES Bethesda Yakkum).

Katuuk, M. E., \& Kallo, V. D. (2019). Hubungan Motivasi dengan Efikasi Diri pada Pasien dengan Diabetes Melitus Tipe II di Rumah Sakit Umum GMIM Pancaran Kasih Manado. Jurnal Keperawatan, 7(1).

Muharram, T., \& Maliya, A. (2018). Hubungan Dukungan Keluarga Dengan Kepatuhan Diet Penderita Diabetes Melitus Di Desa Ngrampal Wilayah Kerja Puskesmas Ngrampal Sragen (Doctoral dissertation, Universitas Muhammadiyah Surakarta).

Ramadhani, D. Y., Agusman, F. , \& Hadi, R. (2016). Dukungan Keluarga dan Efikasi Karakteristik, Diri pada Lanjut Usia Diabetes Mellitus Tipe 2 di Kelurahan Padangsari, Semarang. Jurnal Ners Lentera. Retrieved from http://journal.wima.ac.id/index.php/NERS/article /view/877

Rosikhoh, N. I. (2016). Gambaran penderita gangren dan identifikasi faktor pemicu kejadian gangren pada penderita diabetes mellitus. Skripsi
Sari, C. W. M., Haroen, H., \& Nursiswati. (2016). Pengaruh Program Edukasi Perawatan Kaki Berbasis Keluarga terhadap Perilaku Perawatan Kaki pada Pasien Diabetes Melitus Tipe 2. JKP, Volume 4, 305-315. Retrieved from

http://jkp.fkep.unpad.ac.id/index.php/jkp/article/ view/293/143

Sihombing, D., Nursiswati, \& Prawesti, A. (2012). Gambaran Perawatan Kaki dan Sensasi Sensorik Kaki Pada Pasien Diabetes Melitus Tipe 2 di Poliklinik DM RSUD. Jurnal.Unpad.Ac.Id. https://doi.org/10.1016/j.cyto.2013.02.019

Silolonga, W. N. (2018). Adaptasi dan Pengembangan Instrumen Diabetes Self Efficacy Scale (DSES) Versi Indonesia untuk penderita Diabetes Melitus Tipe 2. makasar. Retrieved from http://digilib.unhas.ac.id/uploaded_files/tempora ry/DigitalCollection/ODgOZDZhM2lzNDJhMzkz MjczNDgyNjM4NmE5ODAOYmRjMjRmM2VIZQ $==$.pdf

Soegondo, S. (2015). Penatalaksanaan Diabetes Melitus Terpadu. : FKUI. https://doi.org/10.1109/ICASSP.1998.681575

Sukmaningsih, W. R. (2016). Faktor Resiko Kejadian Diabetes Melitus Tipe II di Wilayah Kerja Puskesmas Purwodiningratan Surakarta. Publikasi IImiah Jurusan Kesehatan Masyarakat Fakultas IImu Kesehatan Universitas Muhammadiyah Surakarta. Retrieved from http://eprints.ums.ac.id/42800/1/naskah publikasi.pdf 
Meningkatkan motivasi dan efikasi diri penderita diabetes tipe 2 dalam pencegahan kaki diabetik menggunakan dukungan kelompok

Syailendrawati, S. P., \& Endang, R. S. S. (2012). Pengaruh Keterlibatan Aktif dalam Kelompok Dukungan (Persadia) terhadap Tingkat Kepatuhan Pengobatan Penderita Diabetes Mellitus di Puskesmas Pakis Surabaya. Jurnal Psikologi Klinis dan Kesehatan Mental, 1(02).

Winahyu, K. M., Badawi, A., \& Setyoningrum, R. (2016). Hubungan Antara Motivasi Dengan Efikasi Diri Pada Pasien Diabetes Mellitus Tipe 2 Di Persadia Salatiga. Jurnal Keperawatan Medikal Bedah. Retrieved from https:/Jurnal.unimus.ac.id/index.php/JKMB/artic le/view/1105

Zimmerman, B. J. (2000). Self-Efficacy: An Essential Motive to Learn. Contemporary Educational Psychology, 25. Retrieved from https://www.sciencedirect.com/science/article/pi i/S0361476X99910160
World Health Organization. (2016). Global Report

On Diabetes. Retrieved from https://apps.who.int/iris/bitstream/handle/10665/ 204871/9789241565257_eng.pdf;jsessionid=25 997E172F338F45A91E50AD49DA90F2?seque nce $=1$

Yuanita, A., Wantiyah, W., \& Susanto, T. (2014). Pengaruh Diabetes Self Management Education (DSME) terhadap Resiko Terjadinya Ulkus Diabetik pada Pasien Rawat Jalan dengan Diabetes Mellitus (DM) Tipe 2 di RSD dr. Soebandi Jember. Jurnal Pustaka Kesehatan, Vol 2 No 1. Retrieved from https://jurnal.unej.ac.id/index.php/JPK/article/vi ew/607/435 